\title{
PENGEMBANGAN SISTEM INFORMASI GEOGRAFIS BERBASIS LOCAL GENIUS SUBAK UNTUK SISTEM DRAINASE WILAYAH MONANG-MANING, KECAMATAN DENPASAR BARAT, KOTAMADYA DENPASAR
}

\author{
Oleh \\ I Gede Adi Saputra Yasa \\ Jurusan Pendidikan Teknik Informatika
}

\begin{abstract}
ABSTRAK
Penelitian ini bertujuan (1) mendeskripsikan permasalahan sistem drainase wilayah Monang-maning. (2) Merancang jalur saluran sistem drainase dengan berbasis local genius subak. (3) Mengimplementasikan model rancangan sistem drainase berbasis local genius subak khususnya untuk jalur saluran wilayah Monang-Maning Kecamatan Denpasar Barat, Kotamadya Denpasar dengan memanfaatkan Sistem Informasi Geografis.

Penelitian ini menggunakan metode pengembangan perangkat lunak yaitu System Deveploment Life Cycle (SDLC) yang dibagi menjadi 5 (lima) tahapan secara siklus yaitu Planning, Analysis, Design, Implementation dan Maintenance.

Penelitian ini menghasilkan beberapa produk sesuai dengan tujuan penelitian yaitu (1) paparan permasalahan sistem drainase di wilayah Monang-maning meliputi limbah buangan ke sungai, alih fungsi lahan, bangunan utilitas, pelanggaran garis sempadan sungai, sedimentasi, persempitan sungai/saluran, akibat peningkatan jalan banyak lubang trotoar/kanstin menyempit bahkan hilang sama sekali, (2) jenis saluran sistem drainase berbasis local genius subak yaitu transformasi telabah gedeltelabah aya ke saluran primer drainase sebanyak 9 saluran, transformasi telabah pemaron gede ke saluran sekunder drainase sebanyak 16 saluran dan transformasi telabah pemaron cenik ke saluran tersier drainase sebanyak 27 saluran, jumlah bangunan bagi untuk saluran-saluran drainase berbasis local genius subak wilayah Monang-maning adalah 7 inlet-outlet control primer, 23 inletoutlet control sekunder dan 28 inlet-outlet control tersier. (3) implementasi perangkat lunak menggunakan perangkat lunak MAPINFO, MySQL 5, VB 6 dan ODBC 5.3. Perangkat lunak menyajikan rancangan saluran utama, sekunder dan tersier, arah masing-masing saluran dan alat-alat penghubung setiap salurannya
\end{abstract}

Kata - kata kunci: Sistem Informasi Geografis, Subak, Sistem Drainase, Local Genius.

\begin{abstract}
This study was aimed to (1) describe the problems in the drainage system in Monang Maning area, (2) design the waterway of the drainage system based on subak local genius, and (3) implement the design model of drainage system based on subak local genius, especially for the route along Monang Maning area, in West Denpasar district - Denpasar municipality, by using the Geography Information System.
\end{abstract}


This research used the software development method called System Development Life Cycle (SDLC), which was divided into 5 cycled phases; Planning, Analysis, Design, Implementation and Maintenance.

This study produced some products based on the purposes of the study; (1) the description of the problems in the drainage system in Monang Maning which included the waste disposal into the water, the land exploitation, the utilization of the buildings, the trespassing over the river border sign, sedimentation, the constriction of the river or waterway, and the constriction or the loss of the water holes on the pavement due to the raising of the street height, (2) the waterway of the drainage system based on subak local genius, which involved the transformation of telabah gede / telabah aya into 9 (nine) primary drainage waterways, the transformation of telabah pemaron gede into 16 (sixteen) secondary drainage waterways and the transformation of telabah pemaron cenik into 27 tertiary drainage waterways, in which the division buildings for the drainage waterways based on subak local genius in Monang Maning were 7 primary inlet-outlet control, 23 secondary inletoutlet control and 28 tertiary inlet-outlet control, (3) the implementation of software using MAPINFO, MySQL 5, VB 6 and ODBC 5.3 software. The software presented the primary, secondary and tertiary waterway design, the direction and the connectors on each waterway.

Key-words: Geography Information System, Subak, Drainage System, Local genius

\section{PENDAHULUAN}

Sistem drainase bertugas untuk mengalirkan air dari suatu tempat ke tempat lain. Sistem drainase menyebabkan air yang berlebihan tersebut tidak akan diam dan menggenangi daerah tertentu tetapi akan dialirkan.

Monang-maning adalah suatu wilayah dari Kota Denpasar yang sangat padat, daerah ini dari segi lingkungannya juga sangat padat dan sempit. Permasalahan inilah salah satu yang membuat daerah ini sering mengalami kebanjiran. Intensitas banjir yang sangat tinggi, sangat mengganggu aktifitas sekitarnya misalnya sekolah, perekonomian dan perumahan warga. Gatra.com tertanggal 11 Januari 2009 menyatakan.

Pada tanggal 10 Januari - 11 Januari 2009 Kota Denpasar diguyur hujan yang mengakibatkan sejumlah ruas jalan di seputar kota Denpasar berubah menjadi 'sungai akibat saluran got tidak mampu menampung luapan air. Antara melaporkan, lapangan sepak bola di kawasan Perumnas Monang-Maning, Denpasar, berubah seperti 'danau kecil.

Fakta ini juga disebutkan dalam Kapanlagi.com dan Bisnisbali.com tertanggal 12 Januari 2009. Setiap tahunnya, dimusim hujan desa ini selalu mengalami kebanjiran dengan intensitas tinggi.

Penggalian nilai-nilai kearifan lokal yang tertanam dalam sistem subak ini lebih banyak dilakukan dalam hal manajemen pengelolaan air dan lahan persawahan. Melihat karakteristik sistem dan struktur organisasi subak yang begitu lengkap, solid, akurat, efektif

JPTK, UNDIKSHA, Vol. 11 , No. 1, Januari 2014 : 25 - 36 
dan terorganisir, bukan tidak mungkin di dalamnya dapat gali berbagai nilai-nilai kearifan lokal yang mendasari bidang sistem drainase.

Pemanfaatan Local Genius subak seperti yang dipaparkan di atas juga mampu dituangkan dalam teknologi. Suatu sistem yang mampu menuangkan sistem drainase dan sistem subak ke dalam perkembangan teknologi sekarang adalah sistem yang bernama Sistem Informasi Geografis (selanjutnya disingkat SIG).

1. Rumusan Masalah.

Berdasarkan latar belakang yang telah dijabarkan, maka adapun rumusan masalah yang akan dibahas adalah sebagai berikut.

a. Apa saja yang menjadi permasalahan dari sistem drainase wilayah Monang-maning?

b. Bagaimanakah rancangan jalur saluran sistem drainase dengan berbasiskan local genius subak wilayah Monang-maning?

c. Bagaimana implementasi model rancangan sistem drainase berbasis local genius subak khususnya untuk jalur saluran wilayah Monang-Maning, Kecamatan Denpasar Barat, Kotamadya Denpasar dengan memanfaatkan Sistem Informasi Geografis?

2. Tujuan.

Dari permasalahan yang dikemukan, maka tujuan yang utama dalam penulisan penelitian skripsi ini adalah sebagai berikut.

a. Mendeskripsikan permasalahan sistem drainase wilayah Monang-maning.

b. Merancang jalur saluran sistem drainase dengan berbasis local genius subak wilayah Monang-maning.

c. Mengimplementasikan model rancangan sistem drainase berbasis local genius subak khususnya untuk jalur saluran wilayah Monang-Maning, Kecamatan Denpasar Barat, Kotamadya Denpasar dengan memanfaatkan Sistem Informasi Geografis.

3. Batasan Masalah.

Batasan masalah dari penelitian ini adalah sebagai berikut.

a. Batas utara wilayah Monang-maning yang dimaksud adalah batas utara dari Desa Tegal Kertha, batas selatannya adalah batas selatan dari desa Tegal Harum, batas timur adalah Tukad Teba dan batas barat adalah Jalan Mahendradata.

b. Perancangan jalur saluran hanya sebatas menentukan jalur tanpa menghitung besarnya saluran dan hal-hal yang terkait dengan debit air seperti kemiringan, besarnya saluran, dan kemiringan saluran. 
c. Dalam pengolahan Sistem Informasi Geografis, hasil pengolahan adalah merupakan pengolahan data vector.

d. Sistem Informasi Geografis yang disajikan diluar konsep local genius subak adalah jaringan jalan desa Tegal Kertha dan Tegal Harum.

4. Manfaat.

Adapun manfaat bagi penulis, lembaga pendidikan, jurusan dan dinas Pemerintah Daerah yang bisa diambil dalam penelitian ini adalah.

a. Bagi peneliti, penelitian ini adalah untuk melengkapi persyaratan dalam perkuliahan, dan menambah jiwa penelitian bagi peneliti.

b. Bagi Pemerintah Daerah Kecamatan Denpasar Barat, Kotamadya Denpasar dalam lebih khususnya wilayah Monang-maning, akan mampu memodelkan sistem drainase yang tepat khususnya dalam penentuan jalur saluran dan diharapkan mampu memberikan gambaran rancangan sistem drainase yang akan dikembangkan berbasis local genius subak.

c. Lembaga dan institusi pendidikan, skripsi ini diharapkan mampu memicu inspirasi lebih lanjut untuk mendayagunakan nilai-nilai kearifan lokal dalam memajukan pendidikan bangsa.

d. Pemerintah dan masyarakat luas, di satu sisi secara tidak langsung dapat lebih membuka wawasan akan nilai-nilai budaya bangsa, turut serta menjaga dan melestarikan nilai-nilai kearifan lokal dari konsep subak.

\section{PEMBAHASAN}

1. Analisis Sistem Drainase.

a. Analisis Permasalahan Sistem Drainase Wilayah Monang-maning.

Beberapa permasalahan yang sering muncul di Kota Denpasar dalam pembuatan dan perawatan sistem drainase khususnya wilayah monang-maning diantaranya permasalahan limbah, alih fungsi lahan, masalah bangunan utilitas, pelanggaran garis sempadan sungai, sedimentasi, pembangunan yang cenderung mempersempit sungai/saluran, peningkatan jalan. b. Analisis Sistem Drainase Berbasis Local Genius Subak.

Sistem subak terdapat jenis irigasi dengan nama Telabah Gede/Telabah Aya. Konsep penerapan telabah gede/telabah aya adalah Telabah gede/telabah aya adalah saluran pembagi dari saluran sungai, Telabah gede/telabah aya bangunan baginya adalah tembuku

JPTK, UNDIKSHA, Vol. 11 , No. 1, Januari 2014 : 25 - 36 
aya, Saluran yang berhak membagi aliran air dari saluran telabah gedeltelabah aya adalah telabah pemaron gede.

Konsep penerapan telabah pemaron gede adalah Telabah pemaron gede adalah saluran pembagi dari saluran telabah aya, Telabah pemaron gede bangunan baginya adalah tembuku pemaron gede, Saluran yang berhak membagi aliran air dari saluran telabah pemaron gede adalah telabah pemaron cenik.

Konsep penerapan telabah pemaron cenik adalah Telabah pemaron cenik adalah saluran pembagi dari saluran telabah pemaron gede, Telabah pemaron cenik bangunan baginya adalah tembuku pemaron cenik.

Pemasukan dan keluaran dalam sistem drainase diatur oleh inlet dan outlet control. Sistem subak sangat mirip dengan sistem tembuku yang diterapkan. Perbedaan yang mendasar adalah dalam sistem subak tembuku memiliki fungsi lebih dari sekedar pemasukan dan pengeluaran, tembuku juga memiliki fungsi mengatur besarnya debit air yang masuk dan keluar. Dalam tembuku, memiliki beberapa jenis tembuku seperti:

1) Tembuku Aya.

Tembuku aya, pada prinsipnya adalah penghubung antara telabah ayaltelabah gede. Selanjutnya dalam sistem ini, alat bagi ini akan dikenal dengan nama Inlet-Outlet Control Primer.

2) Tembuku Pemaron Gede.

Tembuku pemaron gede, pada prinsipnya adalah penghubung antara telabah pemaron gede dan pembagi saluran telabah aya/telabah gede. Selanjutnya dalam sistem ini, alat bagi ini akan dikenal dengan nama Inlet-Outlet Control Sekunder.

3) Tembuku Pemaron Cenik.

Tembuku pemaron cenik, pada prinsipnya adalah penghubung antara telabah pemaron cenik dan pembagi saluran telabah pemaron gede. Selanjutnya dalam sistem ini, alat bagi ini akan dikenal dengan nama Inlet-Outlet Control Tersier.

c. Analisis Perangkat Lunak.

Perangkat lunak ini dibangun untuk menvisualisasikan keadaan sistem drainase berbasis local genius subak. Perangkat lunak yang akan dikembangkan adalah perangkat lunak yang mampu menjalankan perangkat lunak pengolahan sistem informasi geografis Segala aktifitas, yang dapat dilakukan perangkat lunak pengolahan sistem informasi geografis, dapat dilakukan dengan pengembangan perangkat lunak ini. 
Teknik yang digunakan untuk mengolah peta adalah teknik Digitizing untuk mendapatkan koordinat lintang utara dan lintang selatan di permukaan bumi dengan bantuan dari Google Earth, teknik Buffer untuk mengolah data jalan dan teknik pengolahan Object dalam perangkat lunak yang digunakan seperti clip, combine, split, geoprocessing, convert region/polyline dan geocoding.

2. Perancangan Jalur Saluran Sistem Drainase Berbasis Local Genius Subak.

Jaringan jalan yang memiliki lebar relative yang luas dan mampu disaluri saluran utama setalah mengadakan survey lapangan yaitu Jalan Merpati- Mahendradata, Jalan Gunung Batukaru, Jalan Gunung Rinjani, Jalan Gunung Resimuka, Jalan Gunung Indrakila, Jalan Gunung Lempuyang, Jalan Gunung Sari, Jalan Gunung Cemara dan Jalan Buana Kubu.

Perancangan daerah sistem yang dimaksud adalah daerah dibagi menjadi beberapa kawasan yang mengikuti pola pikir subak, yakni membagi kawasan menjadi golongan hulu (daerah hulu), golongan tengah (daerah tengah), golongan hilir (daerah hilir) dan golongan hulu-tengah (daerah hulu-tengah).

Adapun pertimbangan pembagian golongan ini adalah sebagai berikut.

1. Sumber pembuangan air seperti saluran utama drainase dan sungai.

2. Arah aliran air dalam hal ini kemiringan permukaan tanah.

Golongan hulu drainase subak ditentukan dengan cara melihat kemiringan permukaan tanah dan sungai Tukad Mati.

Pertimbangan yang menjadi dasar dibentuknya golongan tengah adalah pada golongan Tengah (daerah tengah) terdapat 4 (empat) saluran pembuangan drainase berbasis local genius subak yang dapat dijadikan aliran air dan kemiringan tanah permukaan dalam golongan tengah (daerah tengah) relative datar sehingga memungkinkan aliran menuju ke saluran utama.

Golongan hilir dipilih melihat kondisi saluran yang terdapat di jalan Gunung Sari dan jalan Gunung Cemara. Saluran utama di jalan ini diharapkan dapat menampung air dikawasan hilir dan juga melihat sungai yang melintang diantara daerah hilir dapat dimanfaatkan.

Golongan Hulu-Tengah terdapat saluran utama di jalan Gunung Rinjani dan saluran sungai. Saluran ini dapat dimanfaatkan sebagai saluran pembuangan disekitar daerah hulu-tengah.

Jenis saluran ini cocok digunakan dengan lebar jalan 4, 5 atau 6 meter. Selain data lebar jalan tersebut, melihat karakteristik kondisi jalan secara langsung, dapat menjadi pertimbangan juga dalam menentukan jaringan jalan yang akan digunakan.

JPTK, UNDIKSHA, Vol. 11 , No. 1, Januari 2014 : 25 - 36 
Saluran tersier dalam penelitian ini digunakan dalam beberapa hal yaitu data jalan yang memiliki lebar yang sangat sempit umumnya 4 meter ke bawah.

- Inlet-Outlet Control Primer yang terdapat dalam setiap daerah yang ada dalam jaringan saluran primer.

- Inlet-Outlet Control Sekunder yang terdapat dalam setiap daerah yang ada dalam jaringan saluran sekunder.

- Inlet-Outlet Control Tersier yang terdapat dalam setiap daerah yang ada dalam jaringan saluran tersier.

3. Perancangan Perangkat Lunak.

Sistem Informasi Geografis wilayah Monang-maning merupakan suatu aplikasi yang memberikan informasi mengenai daerah atau keadaan geografis wilayah monang-maning. Gambaran tentang perangkat lunak yang dikembangkan menggunakan pemodelan UML (Unified Modeling Language).

Dalam sistem informasi geografis ini, user dibedakan menjadi 3 yaitu administrator, operator dan guest.

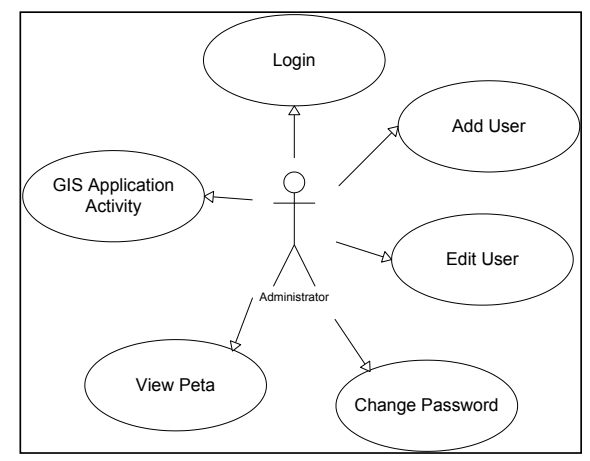

Gambar 1. Use Case Administrator

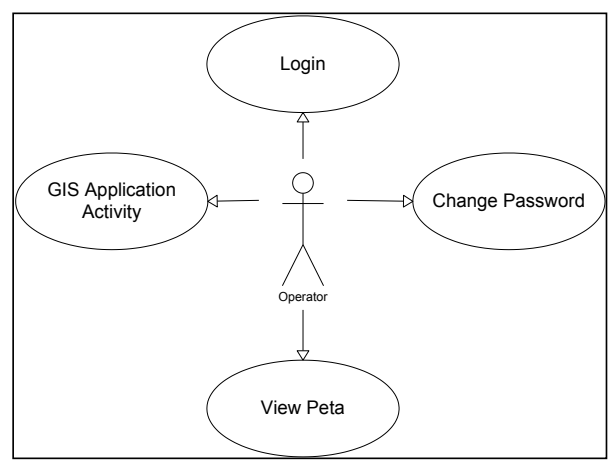

Gambar 2. Use Case Operator

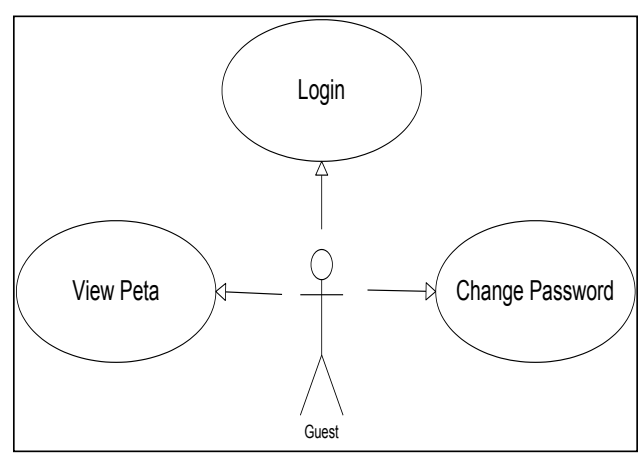

Gambar 3. Use Case Guest 
4. Implementasi Perangkat Lunak.

Perangkat lunak yang digunakan dalam implementasi penelitian ini menggunakan sistem operasi berbasis Windows 32 bit. Perangkat Lunak tambahan yang perlu di pasang dalam komputer yaitu MyODBC 5.3, MAPINFO Profesional 10 dan MySQL 5.

Perangkat keras minimum yang harus ada dalam menjalankan perangkat lunak ini mengikuti permintaan perangkat keras yang diharuskan oleh MAPINFO. Peneliti menggunakan spesifikasi komputer (perangkat keras) sebagai berikut:

a. Proseccor Core 2 Duo 2,1 GHz T8100, 45 Nano

b. Memory 2 GB DDR2 PC 7200

c. ATI Radeon X1200 128 MB

Implementasi dari perangkat lunak meliputi konfigurasi MyODBC 5.3, konfigurasi MySQL dan konfigurasi MAPINFO. Perlu diperhatikan, demi keamanan perangkat lunak, dalam mengkoneksikan MySQL dengan perangkat lunak yang dikembangkan koneksi dengan username dan password dengan MySQL dilakukan di dalam script program. Oleh karena itu, apabila program perangkat lunak ini dijalankan setting terhadap username dan password di MySQL akan mengikuti script yang ada dalam program perangkat lunak. Penulisan script ini menggunakan file external dengan format *ini.

Implementasi rancangan menu untuk membuat menyimpan daftar menu-menu yang digunakan untuk sistem dalam penelitian ini adalah MySQL 5.1. Koneksi yang digunakan untuk menghubungkan MySQL 5.1 dengan bahasa pemrograman VB 6 adalah ODBC 5.1.

File Configurasi Setting yang digunakan bertipe *.ini dengan nama SIG.ini.

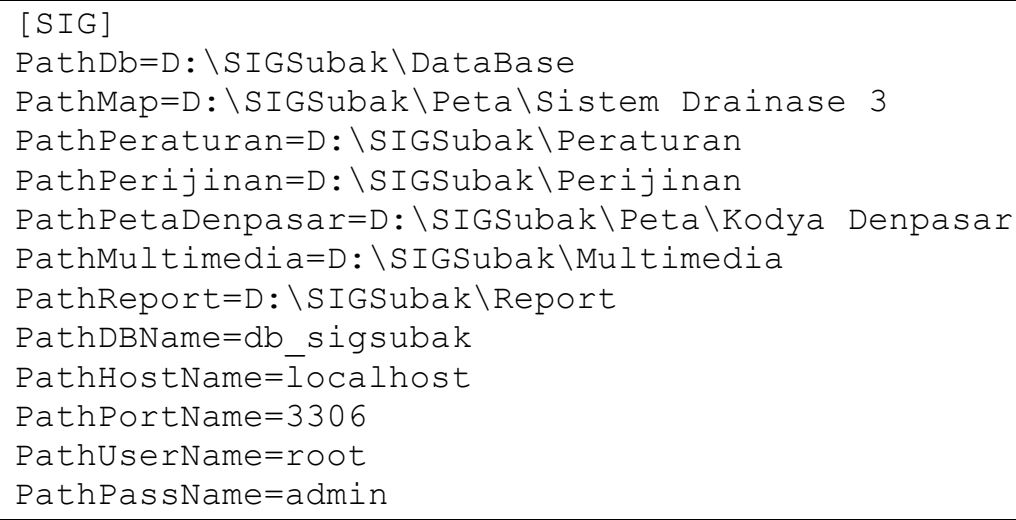

Gambar 4. Script Configuration.

Apabila terjadi perubahan direktori file, setting dalam MySQL maka file SIG.ini harus disesuaikan terlebih dahulu.

JPTK, UNDIKSHA, Vol. 11 , No. 1, Januari 2014 : 25 - 36 


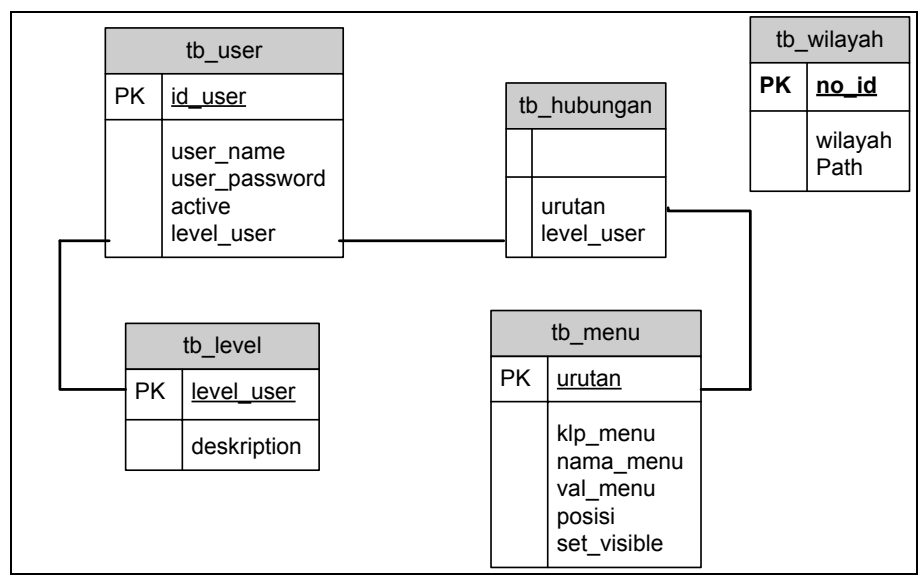

Gambar 5. Relasi Antar Tabel

Berikut adalah script yang digunakan untuk membuat form utama ini.

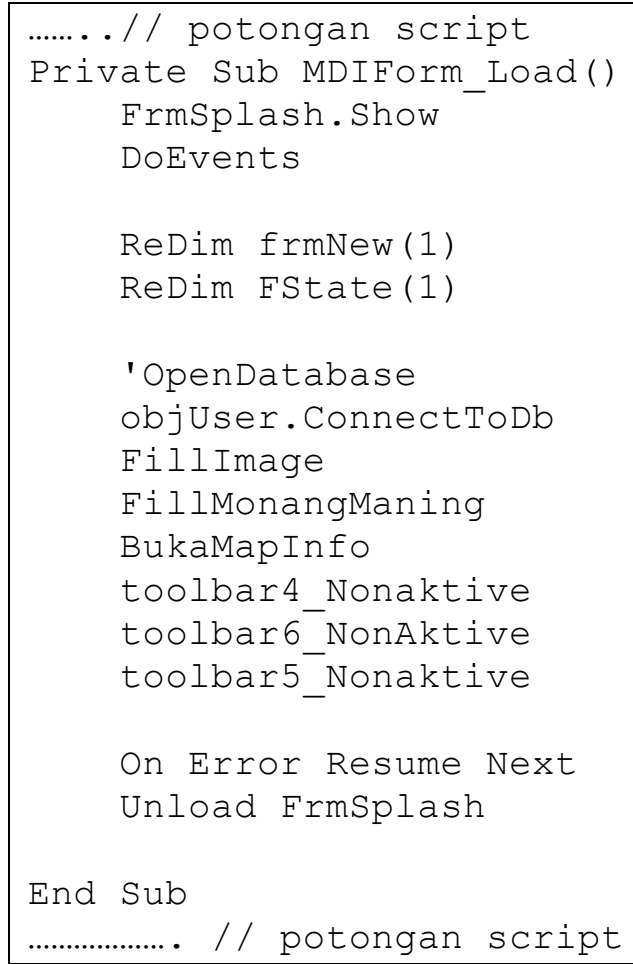

Gambar 6. Script frmMain

Pada script yang diberikan mengenai form utama, dalam laporan ini disajikan adalah sebagian script yang terdapat dalam form utama. Untuk lebih jelasnya mengenai script ini dapat dilihat langsung dalam perangkat lunak. 


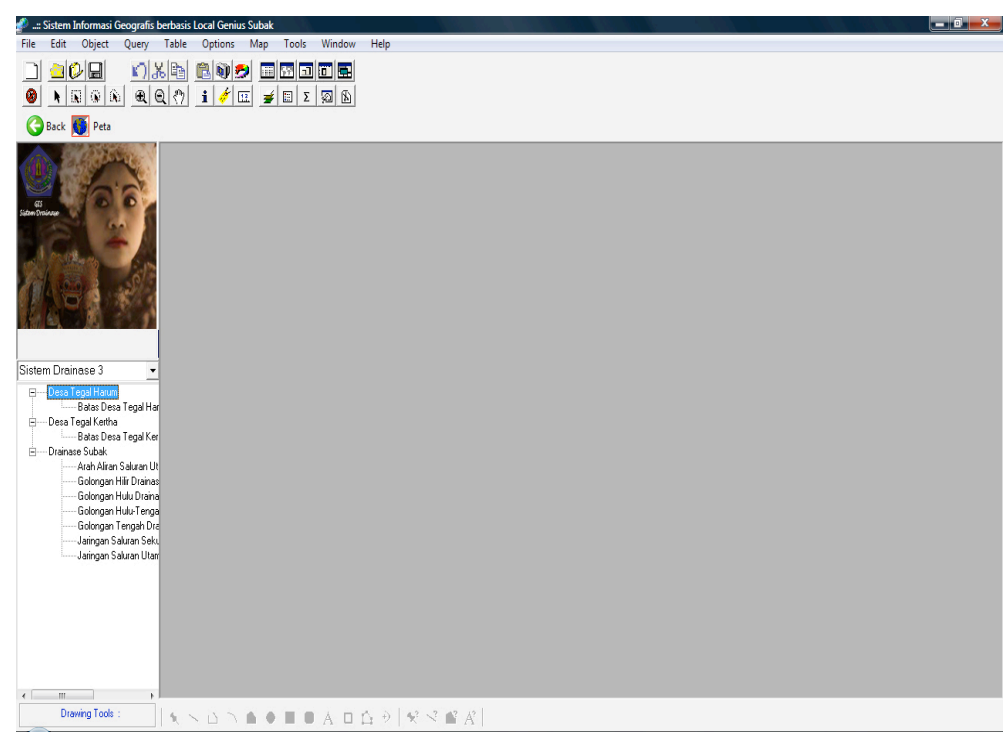

Gambar 7. Form Utama

\section{PENUTUP}

1. Simpulan.

Berdasarkan hasil penelitian yang dilakukan maka, dapat ditarik beberapa kesimpulan diantaranya.

a. Permasalahan yang dihadapi dalam pengelolaan dan pembuatan suatu sistem drainase wilayah Monang-maning adalah

1) Permasalahan limbah yang di buang ke sungai,

2) Masalah alih fungsi lahan,

3) Masalah bangunan utilitas (saluran melintang drainase),

4) Pelanggaran garis sempadan sungai,

5) Sedimentasi yang sangat cepat,

6) Pembangunan yang cenderung mempersempit sungai / saluran dan

7) Akibat peningkatan jalan banyak lobang trotoar / kanstin menyempit bahkan hilang sama sekali.

b. Sistem Subak mampu diadopsi ke dalam sistem drainase khususnya dalam perancangan jalur saluran yang erat kaitannya dengan bangunan-banguna saluran drainase. Berikut adalah perancangan yang dapat diadopsi dari sistem subak.

1) Jenis Saluran 
Saluran Primer, Saluran Sekunder, Saluran Tersier.

2) Wilayah Monang-maning dapat dibagi menjadi 4 kawasan sistem drainase kecil yaitu Golongan Hulu, Tengah, Hilir dan Hulu-Tengah.

3) Bangunan bagi yang menghubungkan setiap jenis saluran adalah Inlet Outlet Control Primer, Inlet Outlet Control Sekunder, Inlet Outlet Control Tersier.

4) Jumlah saluran utama drainase wilayah Monang-maning yang mampu dibuat adalah 9 (sembilan) saluran utama, 16 (enam belas) saluran sekunder, 27 (dua puluh tujuh) saluran tersier.

5) Jumlah bangunan bagi untuk saluran-saluran drainase berbasis local genius subak wilayah Monang-maning adalah 7 (tujuh) Inlet Outlet Control Primer, 23 (dua puluh tiga) Inlet Outlet Control Sekunder dan 28 (dua puluh delapan) Inlet Outlet Control Tersier.

c. Implementasi perangkat lunak menggunakan perangkat lunak MAPINFO, MySQL 5, VB 6 dan ODBC 5.3. Perangkat lunak menyajikan rancangan saluran utama, sekunder dan tersier, arah masing-masing saluran dan alat-alat penghubung setiap salurannya.

\section{Saran}

Dalam penelitian ini, peneliti masih merasa kurang dalam penyajian jalur saluran. Dapat dilihat pada peta hasil pengolahan masih terdapat jalan-jalan yang mungkin kiranya dapat diisi saluran irigasi, namun kenyataannya dalam jalan tersebut peneliti tidak menentukan saluran yang bisa digunakan. Hal ini dikarenakan peneliti kurang mendapatkan data dari jalan tersebut, sehingga peneliti tidak mampu menentukan saluran yang tepat, baik itu dari data dinas terkait ataupun data dari survey langsung yang lebih sering dilakukan peneliti dalam menentukan jalur saluran dan kondisi wilayah tersebut

Implementasi perancangan jalur saluran drainase kiranya nanti dapat diterapkan secara langsung di wilayah Monang-maning. Sehingga dapat menguji keefektifan rancangan ini.

\section{DAFTAR PUSTAKA}

Dinas Perkebunan Provinsi Bali. 2007. "Pembinaan Kelembagaan Petani Perkebunan Di Provinsi Bali Tahun 2007”. www.disbunbali.info. (Tanggal akses : 10 Februari 2009). 
Lembaga Adat. 2007. "Lembaga Adat Gianyar". e-banjar.com. (Tanggal diakses :10 Feb 2009).

S. Pendit Nyoman. 2008. "Nyepi, Kebangkitan, Toleransi dan Kerukunan", books.google.co.id. (Tanggal akses : 10 Februari 2009)

Suripin. 2003 "Sistem Drainase Perkotaan yang Berkelanjutan". Yogyakarta:Andi Yogyakarta.

JPTK, UNDIKSHA, Vol. 11 , No. 1, Januari 2014 : 25 - 36 